\title{
Dosage strength is associated with medication persistence with Ginkgo biloba drug products: a cohort study of ambulatory drug claims data in Germany
}

Sittah Czeche ${ }^{1 \dagger}$, Katrin Schüssel $^{1 \dagger}$, Alexandra Franzmann ${ }^{1}$, Martin Burkart $^{2}$ and Martin Schulz ${ }^{1 *}$

\begin{abstract}
Background: Ginkgo biloba drugs (Gb) are reimbursed within the German statutory health insurance (SHI) scheme for treatment of dementia. In 2008, a novel Gb product containing 240 mg Ginkgo extract EGb761 ${ }^{\circledR}$ per tablet was introduced aiming to facilitate medication use by incorporating the recommended daily dose in one single tablet. The aim of this study was to evaluate the relationship between dosage strength and persistence in a representative population of patients treated with Gb.

Methods: Retrospective cohort study in ambulatory drug claims database within the German SHI system. Persistence was defined as continuous treatment with an allowable gap of 20\% between refills. Multivariate regression models were conducted to identify variables associated with persistence.

Results: Among 13,810 patients initiating treatment with $\mathrm{Gb}$ in 2008, 430 (3.1\%) received a dosage strength of $240 \mathrm{mg}, 7,070(51.2 \%)$ a dosage strength of $120 \mathrm{mg}$ and 6,310 (45.7\%) dosage strengths containing less than $120 \mathrm{mg} \mathrm{Gb}$ per tablet. After 6 months, persistence was highest for patients treated with the $240 \mathrm{mg}$ dosage form (22.8\% of patients), although persistence was low in general (5.7\% and $0 \%$ of patients treated with $120 \mathrm{mg}$ and less than $120 \mathrm{mg}$, respectively). Risk for non-persistence was reduced in patients receiving $240 \mathrm{mg}$ products compared to $120 \mathrm{mg}(\mathrm{HR}=0.63 ; 95 \% \mathrm{Cl} 0.57-0.70)$.

Conclusions: Patients initially treated with $\mathrm{Gb} 240 \mathrm{mg}$ were more persistent compared to those receiving lower dosage strengths. Nevertheless, persistence with Gb therapy is generally low and should be improved in order to better realize therapeutic effects.
\end{abstract}

Keywords: Ginkgo biloba, Adherence, Persistence, Prescription, Drug claims database, Cohort study

\section{Background}

Dementias are diseases of old age and will gain importance with increasing life expectancy. Today, 1.3 million people with dementia live in Germany with an incidence of about 200,000 per year [1]. It is assumed that dementia results in a major burden to health care systems and society as a whole [2]. So far, there is no cure for dementias but several compounds have been approved for symptomatic

\footnotetext{
* Correspondence: m.schulz@dapi.de

${ }^{\dagger}$ Equal contributors

'German Institute for Drug Use Evaluation (DAPI), Jägerstrasse 49/50, 10117 Berlin, Germany

Full list of author information is available at the end of the article
}

treatment to improve cognitive abilities, other mental functions, and activities of daily living: cholinesterase inhibitors (ChEI), the non-competitive NMDA receptor antagonist memantine and standardized Ginkgo biloba dry leaf extracts (Gb) [3].

In Germany, $\mathrm{Gb}$ is approved as a non-prescription drug for the symptomatic treatment of mental losses due to organic brain syndrome within the framework of a general therapeutic concept in case of progressive impairment or loss of mental capacities (dementia syndrome), for vertigo, for tinnitus and for peripheral arterial occlusive disease. However, only the treatment of dementia is a reimbursable indication within the German statutory 
health insurance (SHI) system. The exact mechanisms of action of $\mathrm{Gb}$ have not been established so far, but effects of $\mathrm{Gb}$ constituents on mitochondrial function are being discussed $[4,5]$. From clinical trials with $\mathrm{Gb}$, it has been estimated that $\mathrm{Gb}$ delays progression of symptoms in Alzheimer's dementia by about 6-9 months [6]. In 2008, the German Institute for Quality and Efficiency in Health Care (IQWiG) published a favorable report on the benefit of $\mathrm{Gb}$ in mild-to-moderate Alzheimer's disease for the therapeutic goal 'activities of daily living' [7]. Moreover, an indication of a benefit of Gb regarding 'cognitive function', 'general psychopathological symptoms', and 'quality of life of caregivers' was found. However, the recommendations were restricted to a daily dose of $240 \mathrm{mg}$ and to the ginkgo biloba special extract EGb $761^{\circledR}$. For lower daily doses, there was no conclusive evidence of a benefit.

A recent study among primary care physicians specialized in complementary and alternative medicine in Germany found that prescribing of Gb was strongly associated with diagnosis of Alzheimer's disease versus other types of dementia [8]. Moreover, in this specialized group of physicians, $\mathrm{Gb}$ was the most frequent drug chosen for treatment of dementia in more than two thirds of patients [8]. However, prescribing rates of $\mathrm{Gb}$ in the general SHI population in Germany are much lower with approximately only $14 \%$ of antidementia drug prescriptions or $5,4 \%$ of DDDs constituting Gb drugs $[9,10]$.

It is apparent that the duration of therapy, the continuous supply of the patient with medication as well as the appropriate taking of medication are a prerequisite for efficacy of any drug and thus, for a successful therapy [11]. For drugs to become effective in dementia, treatment duration should be sufficiently long: the European Medicines Agency (EMA) recommends trials of at least 24 weeks to assess a therapeutic effect in dementia for attainment of drug approval [12], and the IQWiG evaluated only trials of a duration of at least 16 weeks for assessment of effectiveness [7]. In placebo-controlled trials with EGb $761^{\circledR}$, therapeutic effects were more pronounced after 24 weeks than after 12 weeks of treatment $[13,14]$.

Non-adherence is a major source of treatment failure [15]. Non-adherence reduces the chance to experience a treatment benefit, and non-appearance of an expected treatment effect can result in premature discontinuation. Reducing the complexity of medication regimens has been found to be one of the most effective measures to improve adherence $[16,17]$. This holds especially true in patients with memory disorders [18].

In 2008, Gb products for the treatment of dementia were available at strengths of $30,40,50,60,80$, or $120 \mathrm{mg}$ per tablet and as drops. To achieve the recommended daily dose of $240 \mathrm{mg}$, two to eight single doses would have been required. Therefore, a novel product containing $240 \mathrm{mg}$ EGb $761^{\circledR}$ per tablet was developed and introduced in 2008 with the aim of facilitating medication use by containing the recommended daily dose in one single tablet.

The aim of this study was to evaluate the relationship between dosage strength and treatment duration (persistence) in a representative population of patients treated with Gb. We hypothesized that persistence is higher with the $240 \mathrm{mg}$ dosage form.

\section{Methods \\ DAPI database}

The study was designed as a retrospective cohort study in the DAPI database (www.dapi.de), which comprises claims data of prescribed drugs dispensed by community pharmacies in Germany at the expense of the SHI funds. For each prescription dispensed, the collected data include a de-identified patient code, the date of prescription, the product identifier $(\mathrm{PZN})$ and the quantity of drug product dispensed. Via the PZN linkage to drug information systems is possible, allowing for characterization of the product with regard to e.g. the amount and type of active ingredient, dosage form, package size etc. Almost 90\% of the German population is covered by the SHI system [19]. The DAPI database contains a representative sample of over $80 \%$ of the community pharmacies throughout Germany. Information about self-medication, drugs at the expense of private health insurance companies, physician samples and drugs dispensed during periods of hospitalization is not available.

The database is not publicly accessible, however studies utilizing data from the DAPI database can be performed on request - subject to the condition that the purpose of the study complies with the DAPI's statutes. The DAPI is a non-profit association aiming at the advancement of scientific research in drug utilization and drug safety.

Ethical approval was not required for the present study, as (i) the data are routinely collected during the process of care without an intervention and (ii) the data comprise deidentified drug claims data being devoid of any personal information, thus precluding re-identification of patients. The database and anonymisation procedures were approved by the responsible data protection authority, at the time of study the regional administrative authority of Darmstadt in Hesse, in compliance with German legislation on data privacy and utilization of data from drug claims.

\section{Study design}

A cohort study was performed comparing three treatment groups according to the dosage strength of the first Gb prescription (index prescription) between January 1st and December 31st 2008:

- patients with an index prescription of $240 \mathrm{mg} \mathrm{Gb}$ dosage strength 
- patients with an index prescription of $120 \mathrm{mg} \mathrm{Gb}$ dosage strength

- patients with an index prescription with a dosage strength of less than $120 \mathrm{mg}$.

Furthermore, patients had to fulfill the following inclusion criteria:

- incident $\mathrm{Gb}$ therapy (i.e. no prescription of $\mathrm{Gb}$ during 365 days before the index date),

- registration in the database 730 to 365 days prior to index date,

- unambiguous assignment to a study group at the index date.

Medical information on the exact indication or comorbidities as well as demographic information is not available in the database. However, reimbursement restrictions within the SHI scheme allow reimbursement of Gb only for dementia. Therefore, it can be assumed that $\mathrm{Gb}$ was prescribed for this indication and not for other labeled indications (such as tinnitus etc.). In addition, the following covariates have been retrieved from the database for further characterization of patients and co-morbidities, and these were also considered as potential risk factors associated with non-persistence:

- medical specialty of initial prescriber: general practitioners, neurologists, internal medicine specialists and other specialties were considered, as prescribing behavior may depend on medical specialty,

- region of the prescriber: western and eastern Germany, as there might be differences in prescribing $\mathrm{Gb}$, because there is a forty years' tradition to prescribe $\mathrm{Gb}$ in the former Federal Republic of Germany (west), but not in the former German Democratic Republic (east),

- insurance membership status at index date: mandatory member, family member or retired person, as this variable is a proxy for the demographic variable age in the database,

- pre-treatment within the 180 days before the index date with

- further antidementia substances (Anatomical Therapeutic Chemical (ATC)-code N06D excluding $\mathrm{Gb}$ ),

- antidepressants (ATC-code N06A),

- nootropics (ATC-code N06BX),

- or drugs indicating the possibility of a co-existing disease for which $\mathrm{Gb}$ may be used but not reimbursed: for indication tinnitus: pentoxifylline (ATC-code C04AD03), for indication peripheral arterial occlusive disease cilostazol (ATC-code B01AC23) and naftidrofuryl (ATC-code
C04AX21), and antivertigo preparations containing betahistine, flunarizine or cinnarizine (ATC-code N07CA).

- Number of different ATC 3rd level codes per patient prescribed within the 180 days prior to index date except those ATC 3rd level codes mentioned above, as the number of different ATC 3rd level codes is supposed to indicate indirectly the degree of co-morbidity.

Patients were excluded if the medical specialty of the prescribed physician, the region or insurance membership status of the index prescription were not available or defined ambiguously.

\section{Outcome}

Persistence was determined as the primary study outcome during 365 days following treatment initiation. It was defined as continuous treatment assuming that any $\mathrm{Gb}$ medication prescribed is completely taken at the recommended dose of $240 \mathrm{mg}$ per day, with temporal lapses between subsequent prescriptions not exceeding an allowable gap of $20 \%$ of the duration of the previous medication supply [20]. Stockpiling, i.e. medication oversupply due to early refill of a prescription, was taken into account in the calculation of persistence. Any switch to another $\mathrm{Gb}$ medication (different drug product and/or different dosage strength) after the index prescription was permitted and was not regarded as treatment discontinuation. If a patient had not refilled a prescription within a predetermined number of days after running out of medication supply plus the allowable gap of $20 \%$, the patient was considered to have discontinued therapy and therefore was classified as non-persistent at the end of the allowable gap [21]. Patients were censored if they were lost to follow-up (i.e. recording of the last prescription of any drug in the database) or at the end of the study period (12 months after the index date). A change of the prescribing physician did not result in loss to follow-up.

The persistence definition requires assumptions about the prescribed daily dose (i.e. $240 \mathrm{mg}$ ). However, the prescribed daily dose is not available in the reimbursement database and may not apply to all patients, e.g. if prescribers deliberately chose a lower dose for an individual patient. Therefore, two additional measures of treatment continuation were employed, which do not depend on a dosage assumption. First of all, the length of therapy was used to calculate the proportion of days covered with $\mathrm{Gb}$ medication from the index date to the date of the last $\mathrm{Gb}$ prescription within the study period (12 months) assuming that the patient had been dispensed enough medication to cover the interjacent period. Patients without a refill prescription were by definition excluded from this analysis. Secondly, the number of patients with at least 
one subsequent refill prescription within 12 months after the index prescription was determined.

Furthermore, we investigated the proportion of patients changing their study group, i.e. who switched between $\mathrm{Gb}$ products of different dosage strengths.

\section{Statistical analyses}

For persistence, length of therapy and refill prescriptions, descriptive statistics (i.e. proportions and median values) were determined. A log-rank test was used to compare persistence between the three study cohorts and Cox proportional hazard models were conducted to identify and control for factors associated with non-persistence. For the analyses of the proportion of patients with a refill prescription, logistic regression models were used. Significance levels were set at $\alpha=0.05$.

All statistical analyses were performed using SPSS for Windows version 14 and $\mathrm{R}$ version 2.13.0.

\section{Results \\ Cohort attrition}

In the DAPI database, 50,995 patients were identified who received at least one prescription of $\mathrm{Gb}$ during the index period between January 1st and December 31st 2008. Pre-treatment with $\mathrm{Gb}$ during 365 days prior to index date was the main reason for exclusion of the majority of patients (i.e. $41.6 \%$ ) from the cohort. Nearly a quarter of patients $(25.3 \%)$ lacked availability in the database in the period of $730-365$ days before index date. After implementation of all inclusion and exclusion criteria, 13,810 patients remained in the final study cohort, of whom 430 patients (3.1\%) were treated with $\mathrm{Gb}$ at a strength of $240 \mathrm{mg}, 7,070$ patients $(51.2 \%)$ at a strength of $120 \mathrm{mg}$ and 6,310 patients (45.7\%) at strengths of less than $120 \mathrm{mg}$ (i.e. $30,40,50,60 \mathrm{or} 80 \mathrm{mg}$ ) at the date of the index prescription (see Figure 1).

\section{Characterization of the final study population}

The baseline characteristics of the study groups are detailed in Table 1 . As Gb with a strength of $240 \mathrm{mg}$ in one tablet had just been introduced on the German market in 2008 [22], the lowest proportion of patients (430 patients or $3.1 \%$ of total study cohort) received prescriptions with this strength, while a similar number of patients were prescribed strengths of $120 \mathrm{mg}$ or less than $120 \mathrm{mg}(7,070$ and 6,310 patients or $51.2 \%$ and $45.7 \%$ of total study cohort, respectively). Generally, Gb medication has mainly been prescribed by general practitioners. However, the proportion of patients receiving prescriptions of $240 \mathrm{mg}$ or $120 \mathrm{mg} \mathrm{Gb}$ strength was higher in the group of neurologists ( $32.3 \%$ and $28.8 \%$ respectively), while physicians of other specialties tended to more frequently issue prescriptions for less than $120 \mathrm{mg} \mathrm{Gb}$ strength. The majority of all patients receiving $\mathrm{Gb}$ were retired $(74.3 \%-82.1 \%)$. Within the pre-treatment period of 180 days before the index date, only few patients received co-medication with drugs for indications possibly related to $\mathrm{Gb}$ use (i.e. antidementia agents, nootropics, drugs used for the treatment of peripheral arterial occlusive disease, vertigo or tinnitus). For example, antidementia agents were used in $8.0 \%$ to $12.6 \%$ of patients. However, pre-treatment with antidepressants was quite common $(38.0 \%-44.4 \%)$. Polypharmacy, defined as prescriptions of 5 or more different ATC 3rd level drugs within 180 days before the index date, was present in approximately $80 \%$ of the patients.

\section{Results of the follow-up period of 365 days}

In the study group treated with $240 \mathrm{mg} \mathrm{Gb}$ at the index date, the proportion of persistent patients was higher compared to the other study groups. Kaplan-Meier curves of treatment persistence with Gb medication until discontinuation of therapy are shown in Figure 2. Differences between the study groups were statistically significant (log-rank test, $\mathrm{p}<0.0001)$. The staircase pattern of the curves results from the different package sizes that were dispensed. Median duration of persistence was 97,73 or 21 days for patients treated initially with $240 \mathrm{mg}, 120 \mathrm{mg}$, or less than $120 \mathrm{mg} \mathrm{Gb}$ dosage strength, respectively. After 6 months, cumulative probability of persistence was $22.8 \%$ for patients treated with $240 \mathrm{mg}$ Gb dosage strength, 5.7\% for $120 \mathrm{mg}$ dosage strength and already close to $0 \%$ for patients treated with less than $120 \mathrm{mg} \mathrm{Gb}$ dosage strength. After 12 months, only $8.4 \%$ of patients with $240 \mathrm{mg} \mathrm{Gb}$ and $2.1 \%$ with $120 \mathrm{mg} \mathrm{Gb}$ were still persistent.

In the unadjusted Cox regression model the risk for being non-persistent was decreased by $37 \%$ for patients treated with $240 \mathrm{mg} \mathrm{Gb}$ dosage strength vs. $120 \mathrm{mg}$ (HR 0.63; 95\% CI: $0.57-0.70$ ), whereas the risk for nonpersistence was increased by 4.5 times for patients treated with less than $120 \mathrm{mg}$ dosage strength vs. $120 \mathrm{mg}$ (HR 4.54; 95\% CI: 4.36 - 4.73). In the adjusted multivariate Cox regression model, further covariates were associated with a reduced risk for non-persistence, e.g. neurologist as medical specialty of prescribing physician at index date, eastern Germany as region of the prescriber or pretreatment with antidementia drugs (see Table 2). Conversely, the hazard for non-persistence was increased for patients with insurance status member or family member (relative to retired persons).

As the persistence method depends on the assumption of a prescribed daily dose of $240 \mathrm{mg}$, further doseindependent measures of treatment continuation were employed. The length of therapy was calculated as the time between the first and last $\mathrm{Gb}$ prescription during the observation period of 12 months after the index date, assuming that the patient had been dispensed enough medication to 


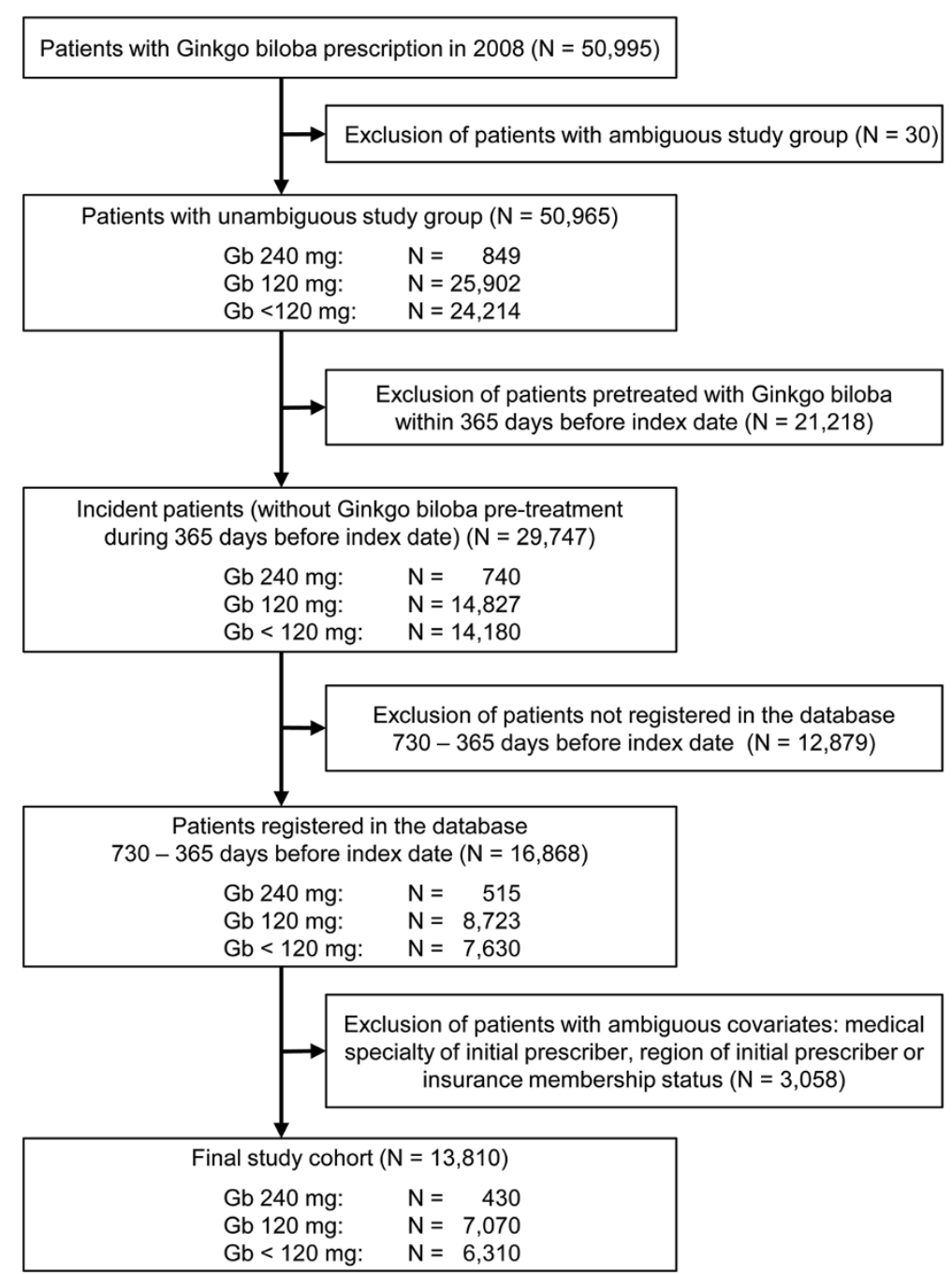

Figure 1 Inclusion and exclusion criteria of the study cohort.

cover the interjacent time period. For this sensitivity analysis, only patients with at least one refill prescription were included (5,583 patients out of 13,810 in the total study cohort). The median of the length of therapy was highest with 281 days in the $240 \mathrm{mg}$ Gb group followed by 250 days in the $120 \mathrm{mg}$ group and 225 days in the group of patients treated with Gb dosage strengths of less than $120 \mathrm{mg}$, confirming the results from the persistence analysis. After 6 months, $68.2 \%$ of the $240 \mathrm{mg} \mathrm{Gb}$ patients, $63.4 \%$ of the $120 \mathrm{mg} \mathrm{Gb}$ patients and $57.9 \%$ of the patients treated with less than $120 \mathrm{mg}$ dosage strengths were considered to be supplied with Gb medication.

As a further dose-independent method we determined the proportion of patients receiving at least one refill prescription after the index date. Again, the proportion of patients refilling at least one prescription was highest (52.8\%) in the group of patients initially treated with $240 \mathrm{mg}$ strength compared to $45.3 \%$ of patients treated with $120 \mathrm{mg}$ and $34.1 \%$ of patients treated with less than $120 \mathrm{mg}$ dosage strength. For logistic regression analysis, only patients with continuous follow-up in the DAPI database for at least 12 months after index date were included (12,191 patients out of 13,810 in the total study cohort). The unadjusted odds for receiving a refill prescription was increased for Gb $240 \mathrm{mg}$ patients by $29 \%$ (OR 1.29; 95\% CI: 1.05 - 1.59) and decreased for less than $120 \mathrm{mg} \mathrm{Gb}$ patients by $37 \%$ (OR 0.63 ; $95 \%$ CI: $0.58-0.68$ ) relative to the group of patients treated with $120 \mathrm{mg} \mathrm{Gb}$ dosage strength. A similar association was found in the adjusted model: The odds to obtain a refill prescription was increased by $28 \%$ for $240 \mathrm{mg}$ Gb patients (OR 1.28; 95\% CI: 1.03 - 1.58) whereas it was decreased by $23 \%$ for less than $120 \mathrm{mg} \mathrm{Gb}$ (OR 0.77; 95\% CI: $0.71-0.83$ ) relative to patients treated with $120 \mathrm{mg} \mathrm{Gb}$ dosage strength.

Similar to the associations observed in the Cox regression analysis of persistence, the covariates internal 
Table 1 Baseline characteristics of the study cohorts

\begin{tabular}{|c|c|c|c|}
\hline & \multicolumn{3}{|c|}{ Number of patients (\% of study group) } \\
\hline & $240 \mathrm{mg}$ dosage strength & $120 \mathrm{mg}$ dosage strength & $<120 \mathrm{mg}$ dosage strength \\
\hline Number of patients & 430 & 7,070 & 6,310 \\
\hline \multicolumn{4}{|l|}{ Medical specialty of initial prescriber } \\
\hline General practitioner & $182(42.3)$ & $3,230(45.7)$ & $2,978(47.2)$ \\
\hline Neurologist & $139(32.3)$ & $2,038(28.8)$ & $887(14.1)$ \\
\hline Internist & $56(13.0)$ & $950(13.4)$ & $896(14.2)$ \\
\hline Other & $53(12.3)$ & $852(12.1)$ & $1,549(24.5)$ \\
\hline \multicolumn{4}{|l|}{ Region of the initial prescriber } \\
\hline Western Germany & $299(69.5)$ & $5,499(77.8)$ & $5,500(87.2)$ \\
\hline Eastern Germany & $131(30.5)$ & $1,571(22.2)$ & $810(12.8)$ \\
\hline \multicolumn{4}{|l|}{ Insurance membership status } \\
\hline Retired & $353(82.1)$ & $5,814(82.2)$ & $4,687(74.3)$ \\
\hline Mandatory member & $62(14.4)$ & $1,029(14.6)$ & $994(15.8)$ \\
\hline Family member & $15(3.5)$ & $227(3.2)$ & $629(10.0)$ \\
\hline \multicolumn{4}{|l|}{ Pre-treatment 180 days prior to index date with } \\
\hline Antidepressants & $181(42.1)$ & $3,136(44.4)$ & $2,395(38.0)$ \\
\hline Antidementia drugs & $54(12.6)$ & $782(11.1)$ & $505(8.0)$ \\
\hline Nootropics & $24(5.6)$ & $379(5.4)$ & $236(3.7)$ \\
\hline Antivertigo preparations (betahistine/flunarizine/cinnarizine) & $50(11.6)$ & $720(10.2)$ & $639(10.1)$ \\
\hline Pentoxifylline & $16(3.7)$ & $372(5.3)$ & $366(5.8)$ \\
\hline $\begin{array}{l}\text { Drugs for treatment of peripheral arterial occlusive disease } \\
\text { (cilostazol/naftidrofuryl) }\end{array}$ & $16(3.7)$ & $189(2.7)$ & $181(2.9)$ \\
\hline $\begin{array}{l}\geq 5 \text { different ATC third level drugs within } 180 \text { days prior to } \\
\text { index date }\end{array}$ & $357(83.0)$ & $5,850(82.7)$ & $5,023(79.6)$ \\
\hline Patients with follow-up prescription & $227(52.8)$ & $3,202(45.3)$ & $2,154(34.1)$ \\
\hline
\end{tabular}

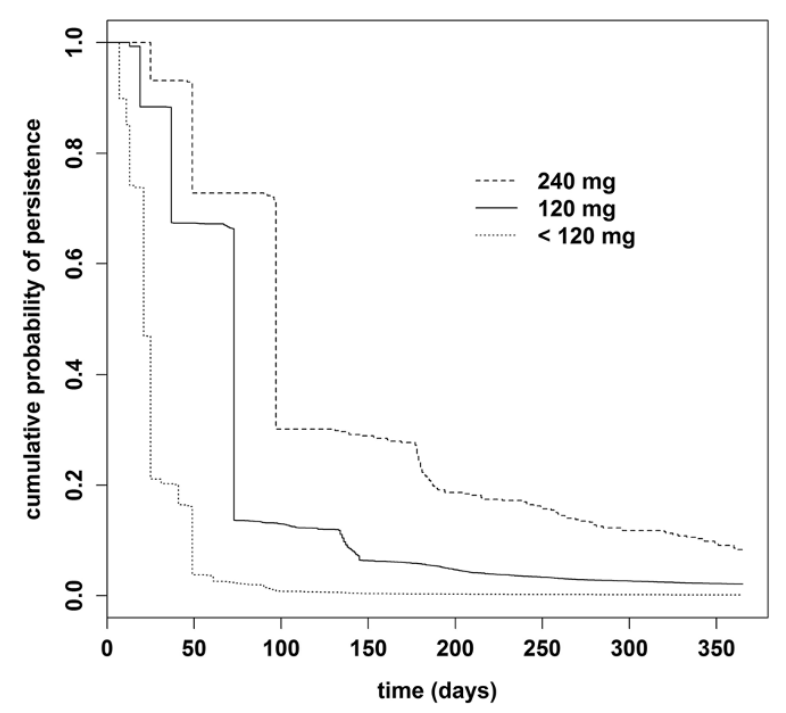

Figure 2 Kaplan-Meier curves showing the cumulative probabilities of continuation of therapy (persistence) in patients treated at index prescription with $\mathrm{Gb}$ at $240 \mathrm{mg}$ dosage strength, $120 \mathrm{mg}$ dosage strength, or less than $120 \mathrm{mg}$ dosage strength. medicine specialist and neurologist, eastern Germany as region of the prescribing physician as well as pretreatment with antidementia drugs were associated with increased odds for a follow-up prescription, while insurance status member and family member were associated with reduced odds for a follow-up prescription relative to retired persons. Further covariates with a positive association of receiving a refill prescription were pre-treatment with antidepressants (OR 1.11; 95\% CI: 1.03 - 1.26) and nootropics (OR 1.46; 95\% CI: 1.23 - 1.73) in the logistic regression model.

However, the results from both regression models are limited by a lack of goodness-of-fit (i.e. the c-statistic for the logistic regression model was only 0.647 ) and in case of the Cox regression models by violations of the proportional hazard assumption.

Finally, switching the dosage strength during follow-up occurred only rarely: in the $240 \mathrm{mg} \mathrm{Gb}$ and less than $120 \mathrm{mg}$ Gb groups, the proportions of patients switching the dosage strength were similar $(13.2 \%$ and $12.9 \%$, respectively), whereas in the $120 \mathrm{mg}$ Gb group merely $7.3 \%$ of patients switched the dosage strength. 
Table 2 Adjusted hazard ratios (HR) for non-persistence and 95\% confidence intervals (CI) in the Cox regression model

\begin{tabular}{|c|c|c|}
\hline & Adjusted HR & $95 \% \mathrm{Cl}$ \\
\hline \multicolumn{3}{|l|}{ Study group (ref. 120 mg Gb dosage strength) } \\
\hline 240 mg Gb dosage strength & $0.64 *$ & $0.57-0.71$ \\
\hline$<120$ mg Gb dosage strength & $4.36 *$ & 4.18-4.54 \\
\hline \multicolumn{3}{|l|}{ Medical specialty of initial prescriber (ref.: general practitioner) } \\
\hline Neurologist & $0.93 *$ & $0.89-0.97$ \\
\hline Internist & 0.96 & $0.91-1.01$ \\
\hline Other & $1.43 *$ & $1.36-1.50$ \\
\hline \multicolumn{3}{|l|}{ Region of initial prescriber (ref.: Western Germany) } \\
\hline Eastern Germany & $0.74 *$ & $0.71-0.77$ \\
\hline \multicolumn{3}{|l|}{ Insurance membership status (ref:: retired) } \\
\hline Mandatory member & $1.23 *$ & $1.17-1.29$ \\
\hline Family member & $1.61 *$ & $1.50-1.73$ \\
\hline \multicolumn{3}{|l|}{ Pre-treatment 180 days prior to index date (ref.: none) } \\
\hline Antidepressants & 0.97 & $0.93-1.01$ \\
\hline Antidementia drugs & $0.86 *$ & $0.81-0.91$ \\
\hline Nootropics & 0.92 & $0.85-1.00$ \\
\hline Antivertigo preparations (betahistine/flunarizine/cinnarizine) & 0.99 & $0.94-1.05$ \\
\hline Pentoxifylline & 1.07 & $0.99-1.15$ \\
\hline Drugs for treatment of peripheral arterial occlusive disease (cilostazol/naftidrofuryl) & 0.99 & $0.89-1.10$ \\
\hline Number of different ATC third level drugs prescribed within 180 days prior to index date & 1.00 & $1.00-1.00$ \\
\hline
\end{tabular}

\section{Discussion}

In the present study, a large cohort of 13,810 patients was identified from the DAPI database with a first prescription for $\mathrm{Gb}$ medication in 2008. Continuation of drug therapy within 12 months from treatment initiation was generally lower than expected in this cohort, although it was significantly higher in patients initiating therapy with the $240 \mathrm{mg}$ dosage strength. After 6 months, the cumulative probability of persistence of patients in the $240 \mathrm{mg}$, $120 \mathrm{mg}$, or less than $120 \mathrm{mg}$ groups decreased to $57.4 \%$, $22.8 \%$, or nearly $0 \%$, respectively, and after 12 months to $8.3 \%$ in the $240 \mathrm{mg} \mathrm{Gb}$ group and to $2.1 \%$ in the $120 \mathrm{mg}$ Gb group. Likewise, only a low proportion of patients filled a second prescription after $\mathrm{Gb}$ treatment initiation: $52.8 \%$ in the $240 \mathrm{mg}$ dosage strength group, $45.3 \%$ in the $120 \mathrm{mg}$ group and $34.1 \%$ in the less than $120 \mathrm{mg}$ group. In analogy to the measures of persistence and refill prescriptions, the length of therapy was highest for patients treated with $240 \mathrm{mg}$ dosage strength compared to study groups with lower dosage strengths.

These results imply that $\mathrm{Gb}$ drugs containing the recommended daily dose of $240 \mathrm{mg}$ in a single tablet might be favorable for patients' persistence - although according to the current label the tablet should be split and one half taken twice a day [22], i.e. the dosage interval thus remains unaltered compared to twice daily dosing of Gb products with $120 \mathrm{mg}$ dosage strength. Nevertheless, we cannot exclude that patients may use the $240 \mathrm{mg}$ product once daily, as this may be more practicable in real-life settings for patients with cognitive impairment and their care-givers [23]. A simpler and less frequent doses regime may increase patients' adherence [16,17]. The efficacy and safety of a once daily regimen of $240 \mathrm{mg}$ EGb $761^{\circledR}$ has been demonstrated in several major placebocontrolled trials $[13,14]$. Hence, presumed once-daily dosing of the $240 \mathrm{mg} \mathrm{Gb}$ products - albeit contrary to the dosage instructions from the package insert - may in part explain the higher adherence (persistence) observed in the present study.

Noting that treatment duration of dementia should be at least 12 weeks $[7,24]$ the persistence after 3 months may be sufficient only for the $240 \mathrm{mg}$ Gb cohort of patients, whereas it is most probably inadequate for the other study groups. However, we cannot exclude that persistence in real-life is better than calculated from SHI reimbursement data, where data on self-medication are unavailable - especially since $G b$ is available without prescription and the largest share of Gb drugs in Germany is purchased via self-medication [25].

The low persistence levels observed in our study may also be explained by discontinuation of the drug due to side effects. However, serious side effects of $\mathrm{Gb}$ that 
could result in discontinuation of therapy were not observed in previous studies. Results of a meta-analysis have shown that the rates of side effects and discontinuation were not different between EGb $761^{\circledR}$ and placebo [26]. The dropout rates in clinical trials of $\mathrm{Gb}$ have been variable, ranging from $1 \%$ to $62 \%$ [26], which may indicate that other factors, e.g. age, co-morbidities, personality traits [27] or unrealistic expectations on treatment effects may be associated with or explain discontinuation of $\mathrm{Gb}$ treatment.

Direct comparisons of persistence results from this study with other investigations are difficult, because, to the best of our knowledge, other data from large populationbased non-interventional cohort studies with Gb treatment are not available. Nevertheless, persistence of patients with dementia was evaluated for ChEI or memantine, albeit with differences in the definition of persistence, inclusion and exclusion criteria or other operational definitions. A recent study based on SHI data in Germany reported that patients with dementia only rarely received continuous prescriptions with an appropriate dosage in each of four quarter years after treatment initiation: $44 \%$ of patients treated with ChEIs and $15 \%$ of patients treated with memantine [9]. Studies from other countries reported on persistence rates at 12 months of $33.6 \%$ for the ChEI donepezil and rivastigmine in Canada [28] and 45.3\% for the ChEI rivastigmine and galantamine in France [29]. Persistence results from these studies with an allowable gap of 60 days between refills are higher compared to the Gb persistence rates in the present study where a gap of only $20 \%$ was allowed. As the $20 \%$ allowable gap is in all cases considerably lower than 60 days (e. g. for a prescription of 120 tablets with the longest coverage, the $20 \%$ allowable gap are 44 days after depletion of the package), these differences in methodology readily explain the lower persistence observed in our study. In the present study a relatively small gap was chosen, because Gb should be taken continuously with at the utmost only small gaps for its efficacy. Furthermore, instead of an absolute number of days as allowable gap, a relative gap of $20 \%$ was chosen in order to allow for the variable package sizes available on the market.

In the pre-treatment period, a large proportion of patients of all 3 study groups frequently received antidepressants. Findings from various studies have shown that there is evidence for an association between late-life depression and dementia, especially Alzheimer's disease (AD) [30-32]. Still it is not clear whether a depression history is a risk factor for AD or whether neuropathologic changes in AD may result in a depression. However, the close relationship between both diseases could be a possible explanation that nearly half of patients across all three $\mathrm{Gb}$ treatment groups received antidepressants in the present study. Therapy with antidepressants was not associated with persistence and showed only a weak, but positive association with the odds of filling a refill prescription. In conclusion, the use of antidepressants in the present study does not seem to have a negative effect on persistence with $\mathrm{Gb}$ therapy.

The proportion of patients with pre-treatment with any antidementia drug was approximately equal, but low, in all study groups. Thus, it appears that patients in the present cohort suffer from mild to moderate symptoms of dementia, where Gb may be chosen as first treatment option before medication with ChEI or memantine was initiated. Alternatively, other antidementia drugs may not have been considered suitable for patients due to contraindications, interactions, side effects, or other than labeled dementia diagnoses. Although ChEI are among the recommended first-line drugs in the treatment of mild to moderate stages of $\mathrm{AD}$ [33], their use is limited due to side effects such as gastrointestinal disorders, dizziness, anorexia, or tremor [34]. For the group of patients pretreated with antidementia drugs, augmentation of therapy with Gb might have been pursued by the prescriber. There is evidence that a combination of both, ChEI and Gb, may be superior to a monotherapy with only $\mathrm{ChEI}$ or $\mathrm{Gb}$ and will be associated with efficacy and less side effects, as shown in an exploratory trial with donepezil and EGb $761^{\circledR}$ [35].

The present study has several limitations which should be taken into account for interpretation of results. Firstly, because in the database no information about drugs dispensed by community pharmacies without prescription (self-medication) or prescriptions at the expense of private health insurance companies is available, patients may be incorrectly interpreted as non-persistent, as already stated above. This also implies that the observed differences in persistence between different dosage strengths of $G b$ in this study may be biased if $\mathrm{Gb}$ medication acquisition via self-medication is non-differential for the different dosage strengths - although there is neither data available to support or refute this hypothesis. Moreover, patients may have incorrectly been classified as non-persistent due to periods of hospitalization or provision of free medication samples from their physician. Therefore, the persistence of patients taking $\mathrm{Gb}$ would be higher if all routes of medication supplies could have been captured. On the other hand, persistence may be overestimated from claims data, since it is assumed that any medication dispensed is completely taken by the patient, which is probably not the case.

Secondly, as in any observational and non-randomized study, the differences in persistence between the study groups treated with different $\mathrm{Gb}$ dosage strengths may be biased by unmeasured, and hence uncontrolled confounding. For example, a previous study found associations between age, personality factors, cognitive function and $\mathrm{Gb}$ adherence [27]. Such variables were not available in the present study. However, insurance membership 
status as a proxy variable for both socioeconomic status and age was included in the regressions models and an association with improved persistence for retired persons relative to other insurance membership categories was found, which confirms previous findings that socioeconomic factors or age may indeed affect $\mathrm{Gb}$ persistence. Nevertheless, we cannot exclude that confounder control with this proxy variable is still limited.

Furthermore, choice of $\mathrm{Gb}$ dosage strength may be related to physician factors such as prescribing preference, which in turn may be either directly or indirectly associated with different persistence with drug therapy. Little is known about physician prescribing preferences for dementia drugs [9] or more specifically for Gb [8]. Although a recent study reported on neurologists preferentially prescribing other antidementia drugs relative to $\mathrm{Gb}$ [8], data on prescribing preferences with regard to choosing the dosage strength of $\mathrm{Gb}$ are unavailable to the best of our knowledge. Also, direct evidence of an association between physician-related factors and persistence with dementia treatment is lacking, although an observational study reported that medication review by doctors was associated with better medication adherence in elderly patients [36]. The results from the present study suggest (i) that neurologists preferentially prescribe $\mathrm{Gb}$ with higher dosage strengths as well as (ii) that being treated by a neurologist is associated with better persistence, hence a potential confounding effect of physician-related factors on persistence cannot be ruled out. In summary, although available covariates such as specialty of prescribing physician were included in multivariate models in the present study, further important confounders may have been missed and associations between different $\mathrm{Gb}$ dosage strengths and persistence may still be biased by unmeasured confounding [37].

Thirdly, the persistence calculation required assumption of a prescribed daily dose and may not reflect the real daily dose for all patients. However, the dose-independent measures of therapy continuation led to essentially the same conclusions.

A strength of the current study is the size of the DAPI database covering more than $80 \%$ of community pharmacies throughout Germany. Hence, the sample of patients in the current study can be assumed to be representative for the SHI scheme. Moreover, refill persistence - as opposed to patient-reported measures - can be regarded as an objective measure of medication adherence [15].

\section{Conclusions}

The results from this study provide evidence that treatment duration with Gb therapy is insufficient in a significant proportion of patients to receive the achievable benefit of therapy. Physicians and pharmacists alike should make efforts to stress the importance of adequate Gb persistence to patients, caregivers and relatives. Moreover, a dosage strength of $240 \mathrm{mg}$ contained in a single dosage form - i.e. the recommended dosage for treatment of dementia per day - appears to be advantageous, especially for older patients with cognitive impairments who are often in need to take numerous other drugs. This observation deserves confirmation in prospective studies.

\section{Abbreviations}

AD: Alzheimers' disease; ATC code: Anatomical therapeutic chemical code; ChEl: Choline esterase inhibitors; Cl: Confidence interval; DAPI: Deutsches Arzneiprüfungsinstitut e.V. (German Institute for Drug use Evaluation); EMA: European medicines agency; Gb: Ginkgo biloba; HR: Hazard ratio; IQWiG: Institut für Qualität und Wirtschaftlichkeit im Gesundheitswesen (Institute for Quality and Efficiency in Health Care); SHI: Statutory health insurance.

\section{Competing interests}

This study was financially supported by and MB is an employee of Dr. Willmar Schwabe Pharmaceuticals, Karlsruhe, Germany, manufacturer of EGb $761^{\circledR}$.

\section{Authors' contributions}

SC and KS designed the study, developed the study protocol, performed the statistical analyses and drafted the manuscript. AF approved the study protocol and contributed to the statistical analyses. MB initiated the study, contributed to the design and study protocol and critically revised the manuscript for important intellectual content. MS contributed to the study design and study protocol and made substantial contributions to the manuscript. All authors read and approved the final manuscript.

\section{Acknowledgements}

The authors thank ABDATA-Pharma-Daten-Service (Werbe- und Vertriebsgesellschaft Deutscher Apotheker mbH, Eschborn, Germany) for provision of drug information data.

\section{Author details}

'German Institute for Drug Use Evaluation (DAPI), Jägerstrasse 49/50, 10117 Berlin, Germany. ${ }^{2}$ Dr. Willmar Schwabe GmbH \& Co. KG Pharmaceuticals, Willmar-Schwabe-Str. 4, 76227 Karlsruhe, Germany.

Received: 14 November 2012 Accepted: 24 September 2013 Published: 24 October 2013

\section{References}

1. Westphal K: Every year 200,000 new Alzheimer cases. Are you aware of the initial symptoms? MMW Fortschr Med 2010, 152:18.

2. Ballard C, Gauthier S, Corbett A, Brayne C, Aarsland D, Jones E: Alzheimer's disease. Lancet 2011, 377:1019-1031.

3. Ihl R, Frolich L, Winblad B, Schneider L, Burns A, Moller HJ: World Federation of Societies of Biological Psychiatry (WFSBP) guidelines for the biological treatment of Alzheimer's disease and other dementias. World J Biol Psychiatry 2011, 12:2-32.

4. Muller WE, Abdel-Kader R, Fehske CJ, Leuner K: Fundamentals of therapeutic application of EGb 761. Pharm Unserer Zeit 2009, 38:408-416.

5. Lautenschlager NT, IhI R, Muller WE: Ginkgo biloba extract EGb 761(R) in the context of current developments in the diagnosis and treatment of age-related cognitive decline and Alzheimer's disease: a research perspective. Int Psychogeriatr 2012, 24(Suppl 1):S46-S50.

6. Kasper S, Schubert H: Ginkgo biloba extract EGb 761 in the treatment of dementia: evidence of efficacy and tolerability. Fortschr Neurol Psychiatr 2009, 77:494-506.

7. IQWIG: Ginkgohaltige Präparate bei Alzheimer Demenz. 2008. https://www.iqwig. de/download/A05-19B_Abschlussbericht_Ginkgohaltige_Praeparate_bei_ Alzheimer_Demenz.pdf, cited 2012 Nov 13.

8. Jeschke E, Ostermann T, Vollmar HC, Tabali M, Schad F, Matthes H: Prescribing patterns in dementia: a multicentre observational study in a German network of CAM physicians. BMC Neurol 2011, 11:99.

9. van den Bussche $H$, Kaduszkiewicz H, Koller D, Eisele M, Steinmann S, Glaeske G, Wiese B: Antidementia drug prescription sources and patterns after the diagnosis of dementia in Germany: results of a claims data-based 1-year follow-up. Int Clin Psychopharmacol 2011, 26:225-231. 
10. Schwabe U, Paffrath D: Arzneiverordnungsreport 2012. Berlin: Springer Verlag; 2012

11. Claxton AJ, Cramer J, Pierce C: A systematic review of the associations between dose regimens and medication compliance. Clin Ther 2001, 23:1296-1310

12. EMEA: Guidline on medicinal products for the treatment of Alzheimer's disease and other dementias. 2009. http://www.ema.europa.eu/docs/en_GB/ document_library/Scientific_quideline/2009/09/WC500003562.pdf, cited 2012 Nov 13.

13. Ihl R, Bachinskaya N, Korczyn AD, Vakhapova V, Tribanek M, Hoerr R, Napryeyenko O: Efficacy and safety of a once-daily formulation of Ginkgo biloba extract EGb 761 in dementia with neuropsychiatric features: a randomized controlled trial. Int I Geriatr Psychiatry 2011, 26:1186-1194.

14. Herrschaft H, Nacu A, Likhachev S, Sholomov I, Hoerr R, Schlaefke S: Ginkgo biloba extract $E G b 761(R)$ in dementia with neuropsychiatric features: a randomised, placebo-controlled trial to confirm the efficacy and safety of a daily dose of $240 \mathrm{mg}$. J Psychiatr Res 2012, 46:716-723.

15. World Health Organisation: Adherence to long-term therapies. Evidence for action. 2003. http://www.who.int/chp/knowledge/publications/adherence_ full_report.pdf, cited 2012 Nov 13.

16. Laufs U, Rettig-Ewen V, Bohm M: Strategies to improve drug adherence. Eur Heart J 2011, 32:264-268.

17. Laufs U, Bohm M, Kroemer HK, Schussel K, Griese N, Schulz M: [Strategies to improve medication adherence]. Dtsch Med Wochenschr 2011, 136:1616-1621.

18. Arlt S, Lindner R, Rosler A, von Renteln-Kruse W: Adherence to medication in patients with dementia: predictors and strategies for improvement. Drugs Aging 2008, 25:1033-1047.

19. Bundesministerium für Gesundheit: Kennzahlen der Gesetzlichen Krankenversicherung. 2012. http://www.bmg.bund.de/fileadmin/dateien/ Downloads/Statistiken/GKV/Kennzahlen_Daten/Kennzahlen_und_ Faustformeln_Aug_2012.pdf, cited 2012 Nov 13.

20. Cramer JA, Roy A, Burrell A, Fairchild CJ, Fuldeore MJ, Ollendorf DA, Wong PK Medication compliance and persistence: terminology and definitions. Value Health 2008, 11:44-47.

21. Caetano PA, Lam JM, Morgan SG: Toward a standard definition and measurement of persistence with drug therapy: Examples from research on statin and antihypertensive utilization. Clin Ther 2006, 28:1411-1424.

22. Dr. Willmar Schwabe GmbH \& Co. KG: Tebonin ${ }^{\circledR}$ konzent 240 mg. Karlsruhe, Germany: Fachinformation [Summary of Product Characteristics]; 2011.

23. Ihl $R$, Tribanek $M$, Bachinskaya N: Efficacy and tolerability of a once daily formulation of Ginkgo biloba extract EGb 761(R) in Alzheimer's disease and vascular dementia: results from a randomised controlled trial. Pharmacopsychiatry 2012, 45:41-46

24. Arzneimittelkommission der Deutschen Ärzteschaft: Demenz. Arzneiverordnung in der Praxis 2004, 31:1-29.

25. IMS Health: GesundheitsMittelStudie (GMS). PharmaScope. ; 2009.

26. Weinmann S, Roll S, Schwarzbach C, Vauth C, Willich SN: Effects of Ginkgo biloba in dementia: systematic review and meta-analysis. BMC Geriatr 2010, 10:14

27. Jerant A, Chapman B, Duberstein P, Robbins J, Franks P: Personality and medication non-adherence among older adults enrolled in a six-year trial. Br J Health Psychol 2011, 16:151-169.

28. Amuah JE, Hogan DB, Eliasziw M, Supina A, Beck P, Downey W, Maxwell C Persistence with cholinesterase inhibitor therapy in a population-based cohort of patients with Alzheimer's disease. Pharmacoepidemiol Drug Saf 2010, 19:670-679.

29. Pariente A, Pinet $M$, Moride $Y$, Merliere $Y$, Moore N, Fourrier-Reglat A: Factors associated with persistence of cholinesterase inhibitor treatments in the elderly. Pharmacoepidemiol Drug Saf 2010, 19:680-686.

30. Napryeyenko O, Borzenko I: Ginkgo biloba special extract in dementia with neuropsychiatric features. A randomised, placebo-controlled, double-blind clinical trial. Arzneimittelforschung 2007, 57:4-11.

31. Butters MA, Young JB, Lopez O, Aizenstein HJ, Mulsant BH, Reynolds CF III, DeKosky ST, Becker JT: Pathways linking late-life depression to persistent cognitive impairment and dementia. Dialogues Clin Neurosci 2008, 10:345-357.

32. Bachinskaya $N$, Hoerr $R$, Ihl R: Alleviating neuropsychiatric symptoms in dementia: the effects of Ginkgo biloba extract EGb 761. Findings from a randomized controlled trial. Neuropsychiatr Dis Treat 2011, 7:209-215.

33. Farlow MR, Cummings JL: Effective pharmacologic management of Alzheimer's disease. Am J Med 2007, 120:388-397.
34. S3-Leitlinie "Demenzen" (Langversion November 2009). 2009. http://www. awmf.org/uploads/tx_szleitlinien/038-013_S3_Demenzen_lang_11-2009_112011.pdf, cited Nov 132012.

35. Yancheva S, Ihl R, Nikolova G, Panayotov P, Schlaefke S, Hoerr R: Ginkgo biloba extract $\mathrm{EGb} 761(\mathrm{R})$, donepezil or both combined in the treatment of Alzheimer's disease with neuropsychiatric features: a randomised, double-blind, exploratory trial. Aging Ment Health 2009, 13:183-190.

36. Cooper C, Carpenter I, Katona C, Schroll M, Wagner C, Fialova D, Livingston G: The AdHOC Study of older adults' adherence to medication in 11 countries. Am J Geriatr Psychiatry 2005, 13:1067-1076.

37. Schneeweiss S: Confounding. In Pharmacoepidemiology and Therapeutic Risk Management. 1st edition. Edited by Hartzema AG, Tilson HH, Chan KA. Cincinnati: Harvey Whitney Books Company; 2008:273-300.

doi:10.1186/1472-6882-13-278

Cite this article as: Czeche et al:: Dosage strength is associated with medication persistence with Ginkgo biloba drug products: a cohort study of ambulatory drug claims data in Germany. BMC Complementary and Alternative Medicine 2013 13:278.

\section{Submit your next manuscript to BioMed Central and take full advantage of:}

- Convenient online submission

- Thorough peer review

- No space constraints or color figure charges

- Immediate publication on acceptance

- Inclusion in PubMed, CAS, Scopus and Google Scholar

- Research which is freely available for redistribution 